Brit. J. prev. soc. Med. (1966), 20, 172-175

\title{
EFFECT OF ORAL IRON THERAPY ON THE SYMPTOMS OF ANAEMIA
}

\author{
BY \\ P. C. ELWOOD AND M. M. WOOD \\ From the Medical Research Council's Epidemiological Research Unit and \\ Social Psychiatry Research Unit, Cardiff
}

In a study published elsewhere (Wood and Elwood, 1966) the associations between the severity of various symptoms and haemoglobin levels in subjects who took part in a community survey is described. The present paper describes a double-blind randomized clinical trial of the effects on these symptoms of oral iron therapy in a sample of the women seen during the community survey. In addition some limited data relating to a separate trial conducted in severely anaemic women identified in a hospital out-patient clinic are presented.

\section{METHOD}

The main study was based on a sample of women living near a Local Health Authority Clinic in the Rhondda Fawr. During a community survey each woman had attended the clinic for a dental and a medical examination which had included venepuncture, and each had been given a self-administered questionnaire which covered the symptoms commonly attributed to iron deficiency anaemia. All women who had been found to have haemoglobin levels between 10.0 and $13.5 \mathrm{~g} . \mathrm{Hb}$, and a $1: 2$ random sample of those with levels above $13.5 \mathrm{~g} . \mathrm{Hb}$, were asked to co-operate. Those who agreed were allotted at random to either a "treated" or a "placebo" group. The treated women were given tablets of ferrous-carbonate $(200 \mathrm{mg}$. elemental iron per day) and those in the placebo group were given tablets of identical appearance containing no iron. Each woman was initially given sufficient tablets for 4 weeks, and was then visited and given further encouragement and sufficient tablets for a further 4 weeks' treatment. At the end of 8 weeks' therapy, venepuncture was repeated and each woman was given an identical copy of the questionnaire on symptoms used during the initial survey.

On conclusion of this trial all women whose haemoglobin level during the trial had fallen below $10 \mathrm{~g}$., together with those who were judged to have shown an unsatisfactory response to iron, were, through their general practitioner, offered investigation at hospital. In addition, all women whose haemoglobin levels were still below $12.5 \mathrm{~g}$. were given further iron therapy.

The questionnaire, which is more fully described by Wood and Elwood (1966), was in two parts. One part was designed to resemble the method of questioning used in most clinical interviews, and consisted of series of four simple questions answered by "Yes" or "No". This enabled eight symptoms to be graded on an arbitrary 16-point scale. The results presented in this paper all refer to this part of the questionnaire. The other part was much longer and rather unusual as it had been designed to minimize some of the possible sources of serious bias inherent in conventional clinical interviews and questionnaires (Ingham, 1965).

Sufficient justification was not felt to exist for the inclusion in the community trial of women who had been found to have haemoglobin levels below $10 \mathrm{~g}$. To supplement the evidence from this trial, a smaller study was therefore conducted on women with initial haemoglobin levels below $10 \mathrm{~g}$. These women had been referred by general practitioners to a hospital out-patients department for haemoglobin estimations, all of which were made by the observer concerned with the community trial. They were all given iron therapy $(200 \mathrm{mg}$. elemental iron per day for 8 weeks) and each was given before and after treatment the simple part only of the questionnaire on symptoms used in the community trial.

The changes with treatment in the grade of each symptom and in the haemoglobin level were examined, and the associations between them assessed by a correlation technique. If a symptom improves 
with treatment, then the change in its grade will be negative. If a rise in haemoglobin level is accompanied by an improvement in a symptom, the correlation coefficient (" $r$ ") will be negative, and if the association between these changes is strong, the coefficient will approach unity.

\section{RESUlTS}

All of 111 women chosen agreed to take part in the community trial. Of these, three became pregnant, and were omitted. A further four refused to fill in the questionnaire, twelve refused the full course of tablets, two could not be traced after treatment, and one was admitted to hospital. Complete data are thus available for only 89 women, 49 of whom had received the placebo, and forty of whom had received iron. Losses from the trial were therefore relatively high, 14 and 22 per cent. in the placebo and treated groups respectively. A high default rate was not unexpected in view of the high degree of co-operation required from each woman and, though the difference between the groups in this respect is

TABLE I

DISTRIBUTIONS OF PLACEBO AND TREATED GROUPS BY AGE AND INITIAL HAEMOGLOBIN LEVEL

\begin{tabular}{|c|c|c|c|c|c|}
\hline \multirow[b]{2}{*}{ Age (yrs) } & \multicolumn{2}{|c|}{ Group } & \multirow{2}{*}{$\begin{array}{l}\text { Haemoglobin } \\
\text { Level (g.) }\end{array}$} & \multicolumn{2}{|c|}{ Group } \\
\hline & Placebo & Treated & & Placebo & Treated \\
\hline $\begin{array}{l}15- \\
25- \\
35- \\
45- \\
55- \\
65+\end{array}$ & $\begin{array}{r}9 \\
5 \\
11 \\
10 \\
10 \\
4\end{array}$ & $\begin{array}{r}7 \\
7 \\
6 \\
11 \\
6 \\
3\end{array}$ & $\begin{array}{l}10 \cdot 0- \\
12 \cdot 5- \\
13 \cdot 5- \\
14 \cdot 6+\end{array}$ & $\begin{array}{r}16 \\
15 \\
15 \\
3\end{array}$ & $\begin{array}{r}18 \\
13 \\
7 \\
2\end{array}$ \\
\hline Total & 49 & 40 & Total & 49 & 40 \\
\hline \multicolumn{3}{|c|}{$\begin{array}{c}x^{2}=2 \cdot 36 ; \text { d.f. }=5 \\
0.80>P>0.70\end{array}$} & \multicolumn{3}{|c|}{$\begin{array}{c}x^{2}=2 \cdot 38 ; \text { d.f. }=2 \\
0.30>\mathrm{P}>0.20\end{array}$} \\
\hline
\end{tabular}

large, it is not significant (at $P<0.05$, the criterion of significance used throughout).

Differences between the treated and placebo groups in the ages and initial haemoglobin levels of the women who completed the trial do not differ significantly (Table I).

During the trial the mean haemoglobin level in the treated group rose significantly by $0.40 \pm 0.15 \mathrm{~g}$., which is significantly different from a fall which occurred in the placebo group of $0.16 \pm 0.11 \mathrm{~g}$. No symptom, however, showed a significant change in grade with treatment in either group, nor is the sign of the change consistent in either group, and in both groups the correlation coefficients between the change in each symptom and the change in haemoglobin level are very small and their signs inconsistent (Table II). No coefficient is significant except that for "paleness" (which can be considered as a very crude estimation by each woman of her own haemoglobin level), which is just significant in the placebo group. The differences in the mean changes of the symptoms in the two groups show no evidence of a beneficial effect of iron above that of the placebo tablet. In fact, the effect of iron compared with that of the placebo on "paleness" becomes significant, but the signs of the mean changes in the groups indicate that this symptom became worse with iron therapy.

This analysis was repeated, dividing the women into those with the lower initial haemoglobin levels $(10.0-12.4 \mathrm{~g}$.), who would clinically be considered "anaemic", and those with initial levels between 12.4 and $13.4 \mathrm{~g}$. In those with the lower initial levels, there appears to have been a significant improvement in "chest pain" in the women given iron, while a small mean increase in the severity of this symptom occurred in those given the placebo tablet, and the

TABLE II

MEAN CHANGES IN SYMPTOM GRADES AND HAEMOGLOBIN LEVEL, AND CORRELATION COEFFICIENTS (“' $r$ ") BETWEEN CHANGES IN SYMPTOM GRADES AND HAEMOGLOBIN LEVEL IN TREATED AND PLACEBO GROUPS

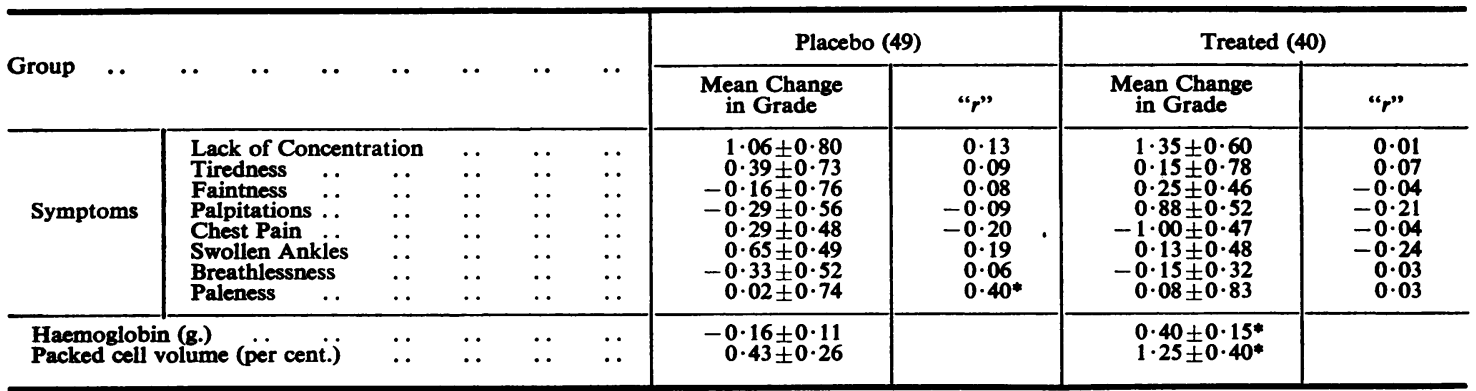

* Significant at $\mathbf{P}<0.05$.

Symptoms graded on an arbitrary 16-point scale.

Note: If a symptom improves, change is negative; if a rise in haemoglobin level is associated with improvement in a symptom, " $r$ " is negative. 
differences in these mean changes in the two groups is significant. "Paleness" showed no significant change in any sub-group, though in women with the higher initial levels the difference between the changes in those given iron and those given the placebo is significant, but not in the expected direction; that is the women who received iron appear to have had an increase in "paleness" compared with those given placebo! The only other significant changes which occurred in these sub-groups was an increase in "tiredness" and "faintness" in the women with the lower initial haemoglobin levels who were given the placebo tablet, but neither of these changes differ significantly from that of the women with similar initial levels who received iron (Table III). However, the numbers in the groups, subdivided in this way by initial haemoglobin level, are very small, though in both sub-groups the mean change in haemoglobin level with treatment in those given iron exceeded that in those given placebo by over $0.5 \mathrm{~g}$. (Table III).

For the sake of space, neither the data from the longer part of the questionnaire, nor data relating to packed cell volumes are given here, but these were all found to be consistent with the results presented.

In the supplementary trial, twenty female hospital out-patients with iron deficiency anaemia were studied. Ten of these had initial haemoglobin levels between 6 and $8 \mathrm{~g}$. and ten between 8 and $10 \mathrm{~g}$. With treatment their mean haemoglobin level rose by $4.47 \pm 0.33 \mathrm{~g}$. The mean changes in the symptoms grades are shown in Table IV. All the symptoms improved on average in this group, though the change was significant only for "lack of concentration" and "tiredness".

\section{Discussion}

The lack of evidence of a significant beneficial effect of iron therapy in our community study, other than "chest pain" in the more anaemic women, is
TABLE IV

MEAN CHANGES IN SYMPTOM GRADES AND HAEMOGLOBIN LEVEL IN TWENTY HOSPITAL PATIENTS GIVEN ORAL IRON THERAPY

\begin{tabular}{|c|c|c|c|}
\hline \multicolumn{3}{|c|}{ Symptom } & Mean Change in Symptom Grade \\
\hline $\begin{array}{l}\text { Lack of Concentra } \\
\text { Tiredness } \quad \ldots \\
\text { Faintness } \quad . \\
\text { Palpitations .. } \\
\text { Chest Pain .. } \\
\text { Swollen Ankles } \\
\text { Breathlessness } \\
\text { Paleness } \quad \text {. }\end{array}$ & $\begin{array}{r}\text { ion } \\
\cdots \\
\cdots \\
\cdots \\
\cdots \\
\cdots \\
\cdots\end{array}$ & $\begin{array}{l}\cdots \\
\cdots \\
\cdots \\
\cdots \\
\cdots \\
\cdots\end{array}$ & $\begin{array}{l}-5.30 \pm 1 \cdot 11^{*} \\
-5.85 \pm 1.49^{*} \\
-2.15 \pm 1.19 \\
-2.95 \pm 1.71 \\
-1.45 \pm 0.69 \\
-0.65 \pm 0.83 \\
-1.65 \pm 0.87 \\
-10.90 \pm 1.35^{*}\end{array}$ \\
\hline Haemoglobin (g.) & . & $\cdots$ & $4 \cdot 47 \pm 0 \cdot 32 *$ \\
\hline
\end{tabular}

* Significant at $\mathbf{P}<0.05$

Note: If a symptom improves, the change will be negative.

surprising and the results are certainly not in keeping with the commonly held clinical concepts of iron deficiency anaemia. We may have failed to detect a beneficial effect of iron therapy with more certainty because we examined the wrong symptoms, or because the method we used to assess a change in symptoms was not sufficiently sensitive, or because the group we studied was not deficient in iron to a sufficient degree. That the first two of these explanations are likely to be incorrect is suggested by the fact that we did detect a significant beneficial effect of iron on "chest pain" in some subjects in the community study, and on "lack of concentration" and "fatigue" in the small series of hospital patients, together with the relative consistency in the results of the latter study. Nevertheless the rather unexpected results for "paleness" in the community trial suggest that the gradient in severity which we intended to imply was not apparent for this symptom in our questionnaire.

Our results are consistent with the hypothesis that only subjects severely deficient in iron show a beneficial change in symptoms with iron therapy. While the results of our study on hospital patients support this hypothesis, these results must be

TABLE III

DIFFERENCES BETWEEN MEAN CHANGE IN SYMPTOM GRADE IN TREATED AND PLACEBO GROUPS (TREATED MINUS PLACEBO) IN SUBJECTS SUB-DIVIDED BY INITIAL HAEMOGLOBIN LEVEL

\begin{tabular}{|c|c|c|c|c|c|c|c|}
\hline Initial Haemoglobin & Cevel (g.) .. & . & . & $\cdots$ & . & $10 \cdot 0-12 \cdot 4$ & $12 \cdot 5-13 \cdot 4$ \\
\hline Symptoms & $\begin{array}{l}\text { Lack of Conce } \\
\text { Tiredness } \\
\text { Faintness } \\
\text { Palpitation } \\
\text { Chest Pain } \\
\text { Swollen Ankles } \\
\text { Breathlessness } \\
\text { Paleness }\end{array}$ & $\begin{array}{l}\text { ntrat } \\
\ldots \\
\ldots \\
\cdots \\
\cdots \\
\ldots\end{array}$ & $\begin{array}{l}\mathbf{n} \\
\cdots \\
\cdots \\
\cdots \\
\cdots \\
\cdots\end{array}$ & $\begin{array}{l}\cdots \\
\cdots \\
\cdots \\
\cdots \\
\cdots \\
\cdots\end{array}$ & $\begin{array}{l}\cdots \\
\cdots \\
\cdots \\
\cdots \\
\cdots \\
\cdots\end{array}$ & $\begin{array}{r}-1 \cdot 19 \pm 1.58 \\
-0.69 \pm 1.50 \\
0.69 \pm 0.97 \\
0.63 \pm 1.35 \\
-2.94 \pm 1.15 * \\
-1.43 \pm 1.15 \\
0.88 \pm 0.79 \\
-2.44 \pm 2.00\end{array}$ & $\begin{array}{r}1 \cdot 38 \pm 1.40 \\
-0.92 \pm 1.59 \\
1.16 \pm 1.81 \\
2.98 \pm 1.80 \\
-1.08 \pm 1.12 \\
0.82 \pm 1.20 \\
0.49 \pm 1.21 \\
3.79 \pm 1.80\end{array}$ \\
\hline Haemoglobin (g.) & . & $\ldots$ & $\ldots$ & $\ldots$ & . & $0.62 \pm 0.37$ & $0.54 \pm 0.26$ \\
\hline
\end{tabular}

* Significant at $\mathrm{P}<0.05$.

Note: If the beneficial effect of iron on a symptom exceeds that of the placebo, the difference will be negative. 
interpreted with considerable caution. Taken by itself this is an exceedingly bad study as almost every possible favourable bias was present, and there were no "control" patients in whom these effects could be assessed. In particular, these women were highly selected, and their selection is likely to have included a large element of self-motivation arising because of symptoms. It is not surprising therefore that the symptom grades in these women were high, and an apparent improvement in symptoms is likely to have occurred both because of "regression towards the mean" (Pearson and Lee, 1903) and because of a spontaneous improvement following investigation and reassurance, independent of any specific effect of iron (the so called "Hawthorne" effect described by Mayo, 1933).

Accepting these limitations, it does appear that the symptoms of iron deficiency which respond to iron therapy may include difficulty in concentration and tiredness, and possibly chest pain. While our studies suggest that these and possibly some of the other symptoms may improve with treatment in subjects with very low haemoglobin levels, there is little evidence that the symptoms of those with initial haemoglobin levels above $10 \mathrm{~g}$. will, on average, benefit from iron therapy. The lack of concordance in the two studies with respect to "chest pain" makes us a little hesitant to accept that the result in the community study for this symptom is valid.

Our findings conflict somewhat with those of Beutler, Larsh, and Gurney (1960) in a similar trial. These workers gave a group of "chronically fatigued, non-anaemic" women, iron tablets and placebo tablets of identical appearance, each for 3 months, the order of the tablets being determined for each woman at random. Few details of the method of assessment of symptoms are given, but it appears that this was based on an "interpretation" of the overall results of conventional clinical interviews without separate consideration of specific symptoms. We cannot adequately explain the difference between our results and those of Beutler and others (1960). It may be that they included only women who initially complained of fatigue, and in whom presumably this and perhaps other symptoms were severe, so that theirs was, in effect, a more sensitive trial than ours. However, if iron therapy causes an improvement in symptoms, then one would have expected women with iron deficiency to benefit symptomatically with iron therapy.

The results of our community study seem to be of considerable importance as they relate to women with haemoglobin levels above $10 \mathrm{~g}$., and it is amongst such subjects that the bulk of the problem of iron deficiency in Great Britain lies (Elwood, 1964; Kilpatrick and Hardisty, 1961). Taken together with the study of Beutler and others (1960), our studies indicate that more work should be done to define more precisely the symptoms of iron deficiency, and the haemoglobin level below which these can be expected to respond to iron therapy. Our results would seem to justify the use of placebo tablets in randomized trials involving subjects with lower haemoglobin levels than those included in our community study.

\section{SUMmaRY}

In the course of a community survey, 89 women were found to have haemoglobin levels above $10 \mathrm{~g}$.; they were given, at random, either $200 \mathrm{mg}$. elemental iron per day, or a placebo tablet of identical appearance. Before and after 2 months' treatment the haemoglobin level was assessed and each of eight symptoms was graded by the use of a selfadministered questionnaire. Although the mean haemoglobin level in the group given iron showed a significant rise, there was no convincing evidence of a significant improvement in any symptom. A supplementary study of twenty hospital patients, in which placebo tablets were not used, suggested that in cases of severe iron-deficiency anaemia oral iron therapy may lead to an improvement in certain symptoms, in particular fatigue and ability to concentrate.

We are grateful to the many people whose co-operation made these studies possible. In particular Prof. A. L. Cochrane and Dr J. Ingham, who advised and assisted throughout, Drs A. Jacobs and J. L. Withey, who accepted responsibility for the haematology, general practitioners in the Rhondda Fawr and Cardiff, who allowed us to approach their patients, Allen and Hanburys Ltd, who supplied the iron ("ferrodic") and the placebo tablets, and Dr G. S. Kilpatrick, to whose out-patients' clinic some of the subjects were referred.

\section{REFERENCES}

Beutler, E., Larsh, S. E., and Gurney, C. W. (1960). Ann. intern. Med., 52, 378.

Elwood, P. C. (1964). Brit. J. prev. soc. Med., 18, 81.

Ingham, J. G. (1965). Brit. J. soc. clin. Psychol., 4, 131.

Kilpatrick, G. S., and Hardisty, R. M. (1961). Brit. med. J., 1, 778.

Mavo, E. (1933). "The Human Problems of an Industrial Civilization". Macmillan, New York.

Pearson, K., and Lee, A. (1903). Biometrika, 2, 357.

Wood, M. M., and Elwood, P. C. (1966). Brit. J. prev. soc. Med., 20, 117. 